\title{
RETENTION OF ARSENIC AND SELENIUM DURING HOT GAS DESULPHURISATION USING METAL OXIDE SORBENTS
}

\author{
Mercedes Diaz-Somoano, M. Antonia López-Antón and \\ M. Rosa. Martínez-Tarazona* \\ Instituto Nacional del Carbón (CSIC), Francisco Pintado Fe, 26, 33011- Oviedo - \\ (Spain) \\ *(rmtarazona@incar.csic.es). \\ *Fax: +34 985297662 \\ *Telephone: +34 985118988
}

Keywords: arsenic, selenium, hot gas cleaning, desulphurisation, coal gasification 


\section{ABSTRACT}

The present work explores the possibility of capturing toxic elements other than sulphur in coal gasification flue gases using metal oxide mixtures. Arsenic and selenium compounds were the elements selected for study because they are toxic species which are present in coal gasification flue gases in different amounts, depending on temperature. Among the regenerable sorbents already developed for hot gas cleaning systems in Integrated Gasification Combined Cycles, metal oxide mixtures based on iron, titanium or zinc oxides (zinc ferrites and zinc titanates) were tested for arsenic and selenium retention. These sorbents have previously proved to possess good characteristics for $\mathrm{H}_{2} \mathrm{~S}(\mathrm{~g})$ retention. The study was carried out in a laboratory scale reactor, using the sorbent in a fixed bed, at $550^{\circ} \mathrm{C}$. Good retention capacities $\left(56 \mathrm{mg} \mathrm{g}^{-1}\right)$ were obtained in these conditions for selenium in a metal oxide mixture containing zinc titanate. A metal oxide mixture containing zinc ferrite proved to be an appropriate sorbent for both elements, retention capacities being $21 \mathrm{mg} \mathrm{g}^{-1}$ for arsenic and $55 \mathrm{mg} \mathrm{g}^{-1}$ for selenium. The results obtained indicate that arsenic and selenium compounds can be retained together with sulphur compounds in these sorbents and be desorbed in the sorbent regeneration processes. 


\section{INTRODUCTION}

The Integrated Gasification Combined Cycle (IGCC) is becoming the preferred way of generating power from coal due to its high efficiency and minimal environmental impact. In this process, over $99 \%$ of the sulphur compounds, particulates and other toxic and corrosive elements in vapour phase must be removed from the coal gas before it reaches the gas turbine. To avoid loss of efficiency, the capture of these species from the coal gas could be carried out while the gas is still hot, and as has already been demonstrated some solid sorbents have good characteristics for the retention of different species at high temperatures.

As regards species in gas phase, sulphur compounds have received most of the attention for environmental reasons. The retention of $\mathrm{H}_{2} \mathrm{~S}(\mathrm{~g})$ in the gasification process can be attained by using various sorbents in different ways. Some of these sorbents are already in use while others are still under development. Among these, Ca-based materials such as limestone and dolomite have proved to have good retention characteristics. These materials are cheap, widely available, and commonly employed to remove sulphur from both combustion and gasification processes. ${ }^{1-3}$ However, they generate a huge quantity of solid residues. An alternative to hot gas desulphurisation in IGCC, is the use of regenerable sorbents such as metal oxides or metal oxide mixtures, because these materials can be used in several cycles and in small quantities. Oxides of iron, zinc, copper and manganese have all been extensively evaluated as both single metal oxides and mixed-metal oxides. ${ }^{3-8}$ Initially studies of gas-solid sulphur adsorption by using metal oxides focused on iron oxides. ${ }^{3}$ Later, zinc oxide-based sorbents were preferred, as zinc oxide possesses highly favourable thermodynamics for reaction with $\mathrm{H}_{2} \mathrm{~S}(\mathrm{~g})$. The early use of $\mathrm{ZnO}$ as a single oxide had the drawback of loss of surface area through sintering and the reduction of $\mathrm{ZnO}$ to $\mathrm{Zn}$ with increased evaporation losses of 
$\mathrm{Zn}$ metal into the gas phase. To avoid these problems, the addition of a second solid in order to stabilize zinc oxide reduction to the metal form was investigated. It was found that by using zinc-ferrites and zinc-titanates, the adsorption capacity and the ability to operate at high temperatures was increased. The major disadvantage of zinc-ferrites is their tendency to form high residual concentrations of iron sulphates and to undergo reductive decrepitation to $\mathrm{FeO}, \mathrm{Fe}$ and $\mathrm{Zn}$ when exposed to highly reductive fuel gas atmospheres. The use of zinc-titanates improved reductive and thermal stability compared to zinc ferrites. ${ }^{3-7}$

Although sulphur retention is considered a major topic in IGCC gas cleaning, other corrosive or toxic species present in gasification flue gases are also of great interest. This is the case of arsenic and selenium, which are classified by the Clean Air Amendments as elements of major environmental concern. ${ }^{9}$ Although arsenic and selenium concentrations in coals range between $0.5-80$ and 0.2-1.4 ppm, respectively, ${ }^{10}$ it has been proved that coal combustion may contribute to the total anthropogenic quantities emitted to the environment. ${ }^{11-13}$ There are no similar data for gasification processes, but it is thought that, as in combustion, during coal gasification arsenic and selenium may form volatile toxic compounds that remain in gas phase at high temperatures, ${ }^{14-16}$ and may be totally or partially released into the environment. As with sulphur, some gas-solid adsorption processes that use different solid materials are also effective for arsenic and selenium retention. ${ }^{17-20}$ However, the most simple and costeffective strategy for removing these elements would be their simultaneous capture in sorbents already in use or being developed for sulphur compounds.

The objective of this work was to evaluate the capacity of zinc-ferrite and zinctitanate based sorbents used for sulphur removal for retaining arsenic and selenium. The ultimate goal was to ascertain the simultaneous retention of toxic elements during 
desulphurization processes using metal oxide sorbents and to investigate the presence of toxic elements other than sulphur in the sorbent regeneration process. The development of multi-pollutant sorbents is currently a subject of major interest, and the possible presence of toxic elements in the metal oxide sorbents from the desulphurization process that may be released during sorbent regeneration, needs to be investigated.

\section{EXPERIMENTAL METHODS AND CONDITIONS}

The metal oxide mixtures used in this work were prepared by the calcination of the commercial oxides $\mathrm{ZnO}(\mathrm{Z}), \mathrm{Fe}_{2} \mathrm{O}_{3}(\mathrm{~F})$ and $\mathrm{TiO}_{2}(\mathrm{~T})$, in an air atmosphere at $650^{\circ} \mathrm{C}$ for 16 hours, following a method developed previously. ${ }^{7}$ The metal oxide mixtures obtained were designated as ZFT(a), ZT and ZF. Sorbents of the ZFT(a) series were subsequently calcined at $1100^{\circ} \mathrm{C}$ to facilitate the progress of spinel formation. ${ }^{7}$ The samples obtained were named ZFT(b). Within each series, mixtures of three different stoichiometries were prepared in order to obtain different chemical compositions and textural properties (Table 1).

The characterisation of the metal oxide mixtures was performed using various techniques. Crystalline species were identified by X-ray Diffraction (XRD) and the morphological study was carried out by Scanning Electron Microscopy (SEM). The particle size was estimated in a Coulter Counter apparatus and the surface area of the solid before and after the thermal treatment was determined by volumetric adsorption of nitrogen at $77 \mathrm{~K}$ using the BET calculation method.

Thermodynamic equilibrium calculations using HSC-Chemistry 4.0 software were employed to predict trace element species in gas phase at work conditions and interactions between the trace element in gas phase and the solid sorbent. 
Table 1. Characteristics of the metal oxide mixtures prepared for this study.

\begin{tabular}{|c|c|c|c|c|}
\hline Group & Sorbent & $\mathrm{Z}+\mathbf{F}+\mathbf{T}$ & $\begin{array}{l}\text { Average size } \\
(\mu \mathrm{m})\end{array}$ & $\begin{array}{l}\text { Surface area } \\
\left(\mathrm{m}^{2} \mathrm{~g}^{-1}\right)\end{array}$ \\
\hline \multirow{3}{*}{ ZFT(a) } & ZFT-1 & $1+0.2+0.8$ & 16.6 & 4.87 \\
\hline & ZFT-2 & $1+0.5+0.5$ & 16.4 & 3.75 \\
\hline & ZFT-3 & $1+0.8+0.2$ & 11.1 & 2.52 \\
\hline \multirow{3}{*}{$\mathrm{ZT}$} & ZT-4 & $2.0+0+3.0$ & 19.1 & 6.98 \\
\hline & ZT-5 & $1.0+0+2.0$ & 24.6 & 7.59 \\
\hline & ZT-6 & $0.8+0+1.0$ & 19.3 & 6.54 \\
\hline \multirow{3}{*}{$\mathrm{ZF}$} & $\mathrm{ZF}-7$ & $0.8+1.0+0$ & 8.99 & 2.11 \\
\hline & ZF-8 & $1.0+1.0+0$ & 10.2 & 1.97 \\
\hline & ZF-9 & $1.2+1.0+0$ & 9.09 & 2.16 \\
\hline \multirow{3}{*}{ ZFT(b) } & ZFT-10 & $1+0.2+0.8$ & 26.9 & 0.12 \\
\hline & ZFT-11 & $1+0.5+0.5$ & 19.3 & 0.30 \\
\hline & ZFT-12 & $1+0.8+0.2$ & 15.5 & 0.27 \\
\hline
\end{tabular}

The retention experiments were carried out in a laboratory scale apparatus using a synthetic gas mixture. The apparatus consisted of a quartz reactor fitted with internal and external tubes and heated by two furnaces (Figure 1). The sorbent and the element source $\left(\mathrm{As}_{2} \mathrm{O}_{3}\right.$ or Se), were placed inside the internal tube but heated separately in the two furnaces. A synthetic gas mixture, typical of coal gasification processes $(57.6 \%$ $\mathrm{CO} ; 3.3 \% \mathrm{CO}_{2} ; 18.8 \% \mathrm{H}_{2} ; 4.0 \% \mathrm{H}_{2} \mathrm{O} ; 0.9 \% \mathrm{H}_{2} \mathrm{~S} ; 15.4 \% \mathrm{~N}_{2}$ ), was passed through the reactor. The gas mixture carried the element compound in vapour phase through the sorbent bed at a flow rate of $0.5 \mathrm{~L} \mathrm{~min}^{-1}$. The element that was not retained in the 
sorbent was captured in impingers containing $\mathrm{HNO}_{3} 0.5 \mathrm{~N}$. The evaporation of the solid sources of the element was carried out at $260^{\circ} \mathrm{C}$ for $\mathrm{As}_{2} \mathrm{O}_{3}$ and $470^{\circ} \mathrm{C}$ for Se to obtain $1 \mathrm{mg} \mathrm{L}^{-1}$ of arsenic and selenium in gas phase. The retention capacities were studied at $550^{\circ} \mathrm{C}$. Under these conditions, solid $\mathrm{As}_{2} \mathrm{O}_{3}$ and Se evaporated at 0.5-0.6 $\mathrm{mg} \mathrm{min}^{-1}$. The sorbent bed was prepared by mixing $1 \mathrm{~g}$ of the metal oxide mixture with $3 \mathrm{~g}$ of sand. The resulting sorbent bed is $2.5 \mathrm{~cm}$ in diameter and $1.1 \mathrm{~cm}$ in height. Before the sorption experiments, the sorbents were subjected to thermal treatment in the same gas composition at $600^{\circ} \mathrm{C}$ in order to control sorbent transformations caused by the high temperatures during the retention experiments. $600-650{ }^{\circ} \mathrm{C}$ is the maximum temperature range at which these solids are stable. Arsenic and selenium retention was evaluated by analysing their amounts in the sorbents after the experiments, using ICP-MS. The quantity of sulphur retained was determined in an automatic analyser LECO S144-DR. To assess the maximum retention capacity (MRC) of the sorbent, a sequence of experiments was conducted, in which the quantity of elements was increased until saturation of the sorbent was achieved.

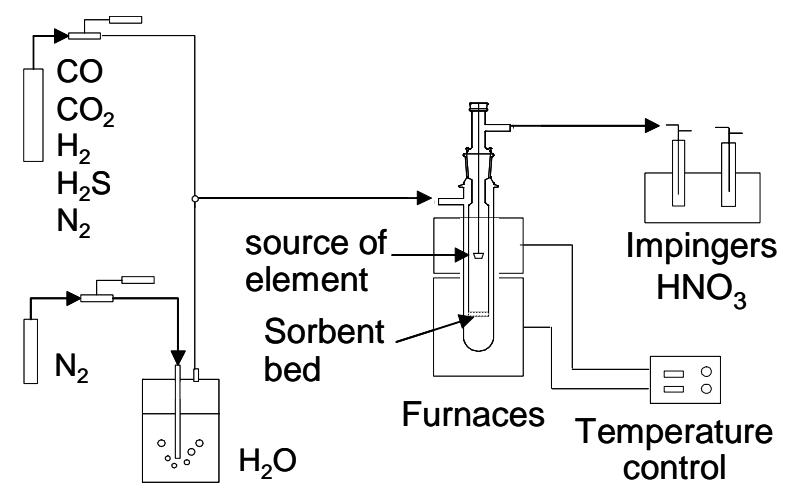

Figure 1. Schematic diagram of the experimental device.

Water solubility tests and thermal stability studies of the post-retention sorbent were also carried out. The water-soluble fraction was determined in an ultrasonic bath 
with Milli-Q water at $40^{\circ} \mathrm{C}$, for two hours. Thermal stability was estimated over a period of three hours in a gasification atmosphere free of the trace element at the same temperature as in the retention experiment. To ascertain the stability of the retained element during sorbent regeneration processes, the post-retention sorbent was heated in an oxygen atmosphere for 6 hours at $600{ }^{\circ} \mathrm{C}$.

\section{RESULTS AND DISCUSSION}

The crystalline chemical species identified by XRD in the metal oxide mixtures after calcination were mainly spinel compounds $\left(\mathrm{Zn}_{2} \mathrm{TiO}_{4}\right.$ and $\left.\mathrm{ZnFe}_{2} \mathrm{O}_{4}\right)$ in the case of $\mathrm{ZT}$; ZF, and ZFT(b) series while in ZFT(a) only a minimum quantity of spinel was detected. $^{7}$ The morphology of these spinel phases can be observed by SEM (Figure 2). The average size and suface area for the different metal oxides mixtures after calcination are given in Table 1. Particle size distribution varies slightly from one mixture to another. The average values range from 9 to $27 \mu \mathrm{m}$, the maximum values being between 30 and $70 \mu \mathrm{m}$. The BET surface area of all the metal oxide mixtures ranged between 0.12 and $7.6 \mathrm{~m}^{2} \mathrm{~g}^{-1}$ (Table 1). The largest areas correspond to the ZT series while values of the ZF series were close to $2 \mathrm{~m}^{2} \mathrm{~g}^{-1}$. For the ZFT(a) series, the specific surface area measured varied between 2.5 and $4.9 \mathrm{~m}^{2} \mathrm{~g}^{-1}$. The lowest values (0.1-0.3 $\left.\mathrm{m}^{2} \mathrm{~g}^{-1}\right)$ corresponded to the ZFT series that had been prepared by calcination at $1100^{\circ} \mathrm{C}$. At this temperature metal oxides sinter, their structures compact, and their porosity disappears.

Two metal oxide mixtures that contain a high proportion of spinel, ZT-6 and ZFT-11, were selected for arsenic and selenium retention. These mixtures had similar medium size particles $(20 \mu \mathrm{m})$ but different surface areas, 6.54 for ZT-6 and $0.30 \mathrm{~m}^{2} \mathrm{~g}^{-1}$ for ZFT-11. After ZT-6 and ZFT-11 had been heated at $600^{\circ} \mathrm{C}$, in the gasification 


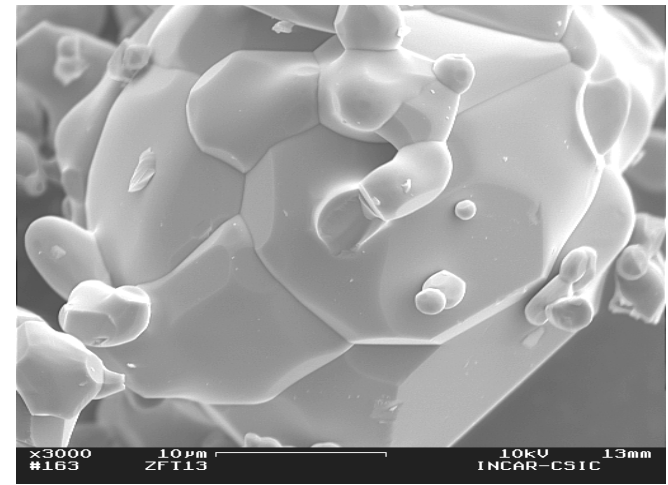

(a)

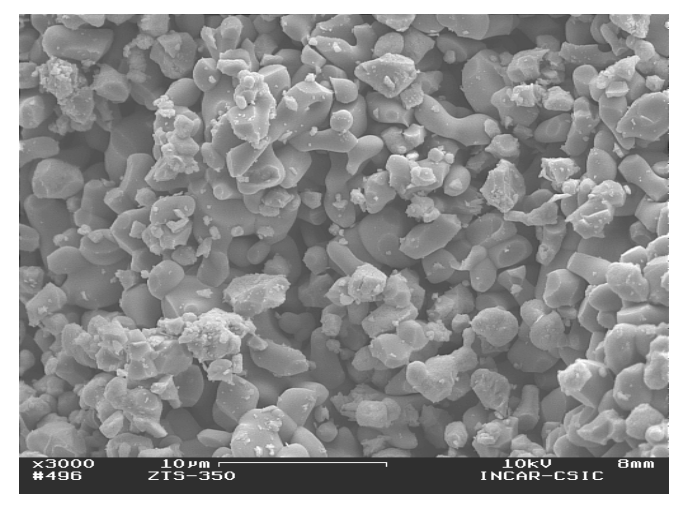

(c)

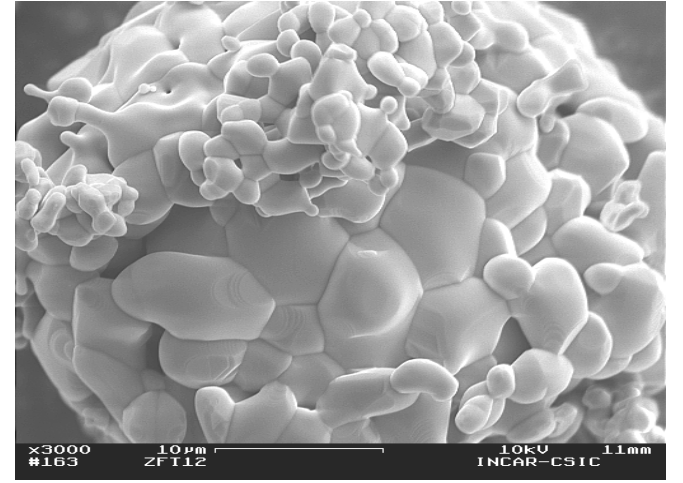

(b)

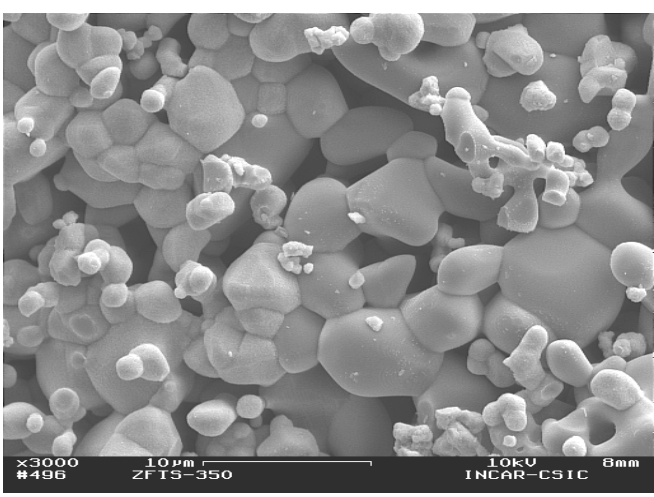

(d)

Figure 2. SEM micrographs (3000 amplifications). (a) ZT-6 and (b) ZFT-11 both before retention experiments; (c) ZT-6 and (d) ZFT-11 after retention experiments.

atmosphere, the surface areas decreased to 0.7 and $0.2 \mathrm{~m}^{2} \mathrm{~g}^{-1}$ respectively. The high temperature and the reducing atmosphere produced certain modifications in the morphology of these solids (Figure 2). These modifications were mainly due to the formation of $\mathrm{FeS}$ or $\mathrm{ZnS}$ from the reactions between the sulphur present in the gas atmosphere and the spinel compound [1-2]. ${ }^{4,6} \mathrm{FeS}$ and $\mathrm{ZnS}$ were identified by XRD

$$
\begin{aligned}
& \mathrm{Zn}_{2} \mathrm{TiO}_{4}+2 \mathrm{H}_{2} \mathrm{~S} \leftrightarrow 2 \mathrm{ZnS}+\mathrm{TiO}_{2}+2 \mathrm{H}_{2} \mathrm{O} \\
& \mathrm{ZnFe}_{2} \mathrm{O}_{4}+3 \mathrm{H}_{2} \mathrm{~S}+\mathrm{H}_{2} \leftrightarrow \mathrm{ZnS}+2 \mathrm{FeS}+4 \mathrm{H}_{2} \mathrm{O}
\end{aligned}
$$

Because it was not possible to identify the arsenic and selenium species present in the gas phase at the temperatures of the experiments, a theoretical approximation was 
performed, using thermodynamic equilibrium models. The results of these theoretical calculations suggest that different arsenic compounds may formed in gas phase depending on temperature, the $\mathrm{As}_{4}(\mathrm{~g})$ species being the most stable at $550{ }^{\circ} \mathrm{C}$ (Figure 3 ). In the case of selenium the most stable species in the whole range of temperatures studied was $\mathrm{H}_{2} \mathrm{Se}(\mathrm{g})$. Trace element concentrations during the retention experiments were higher than the concentrations found in the coal-gasifier stream. When the equilibrium compositions were examined for the influence of trace element concentration, no variations to the most stable species were found.

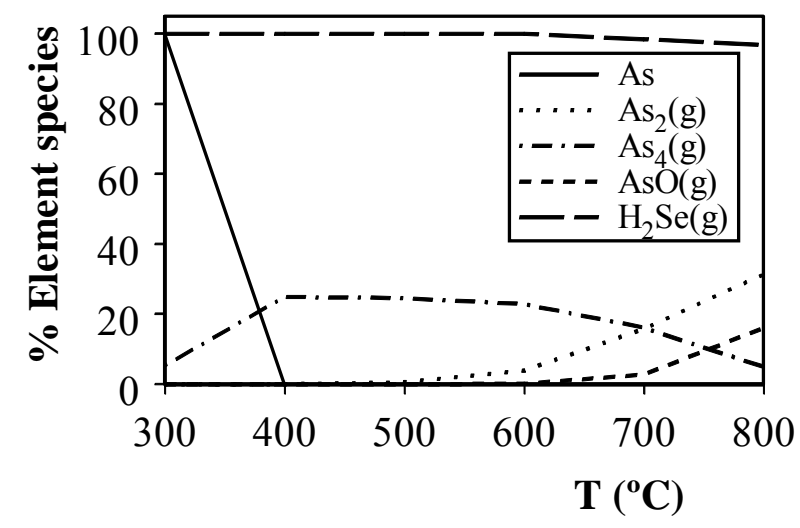

Figure 3. Equilibrium composition for $\mathrm{As}_{2} \mathrm{O}_{3}$ and $\mathrm{Se}$ in the experimental conditions.

Before discussing the results obtained in the retention experiments it should be noted that the experimental procedure was developed with the aim of evaluating and comparing the retention capacities of two different sorbents, using equipment in which the element retained is determined by analyzing the sorbent. The representation of the quantity of element retained against the quantity originally present in gas phase was made using a discontinuous approach (Figure 4). If a rough estimation is made of where the curve separates into two straight lines, two parameters that can be used to compare the behaviour of the sorbents can be inferred for each element: efficiency, defined as the percentage of element retained which is estimated from the slope of the first line, and 

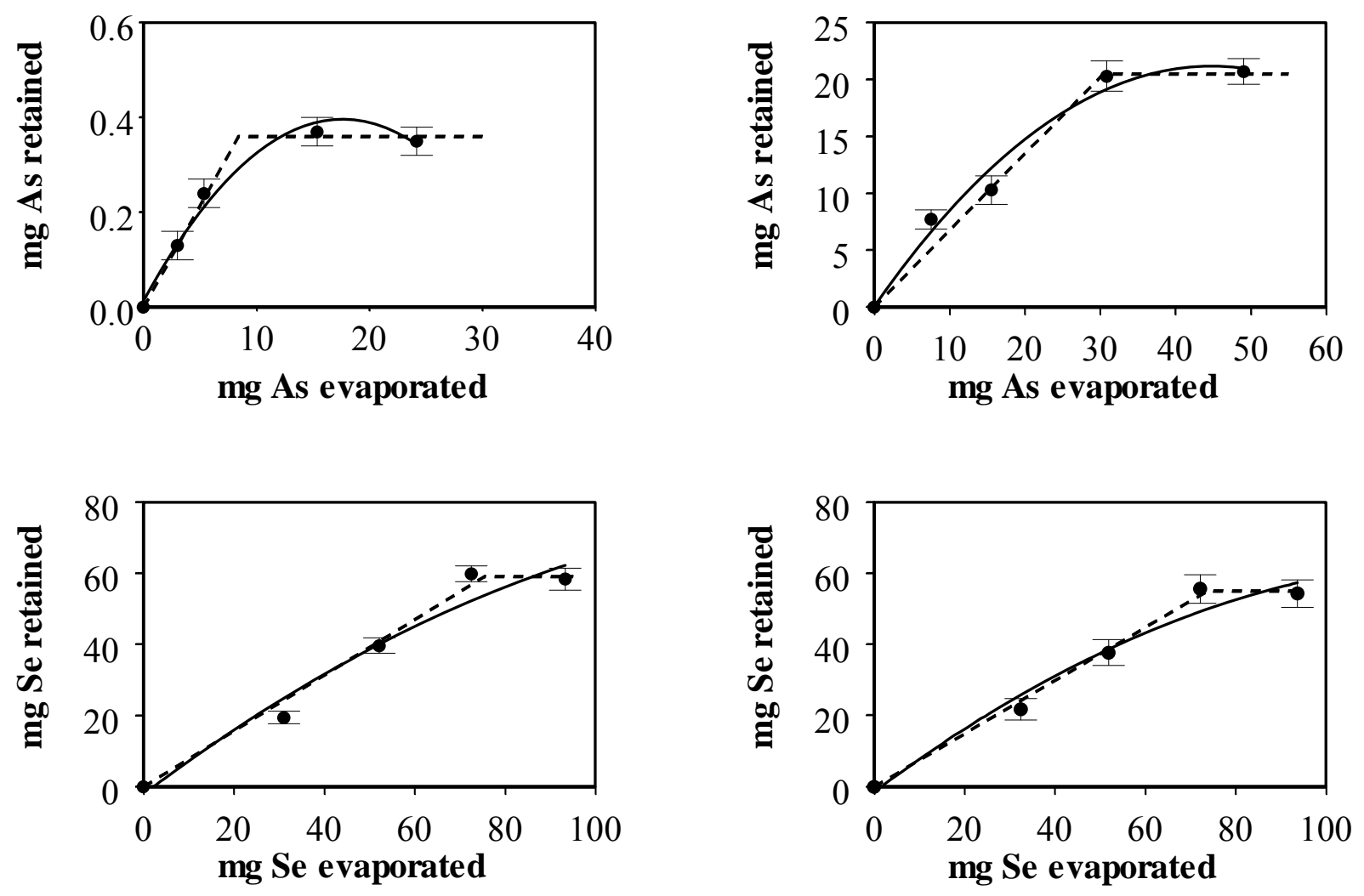

Figure 4. Results obtained during retention experiments for arsenic with (a) ZT-6 and (b) ZFT-11, and for selenium with (c) ZT-6 and (d) ZFT-11

maximum retention capacity, which is the value of the second line parallel to the axis. The values of efficiency and MRC obtained in each case are given in Table 2. The MRC values are lower for arsenic. The ZT-6 metal oxide mixture only retains arsenic in the conditions studied in quantities in the order of $0.35 \mathrm{mg} \mathrm{g}^{-1}$, while in the ZFT-11 metal oxide mixture $21 \mathrm{mg} \mathrm{g}^{-1}$ was attained. In contrast, selenium retention was similar in both metal oxide mixtures, the MRC values being close to $55 \mathrm{mg} \mathrm{g}^{-1}$. Efficiency was also higher for selenium retention than for arsenic, and in general, a higher MRC corresponds to a higher efficiency (Table 2). Maximum efficiency for arsenic was obtained with the ZFT-11 metal oxide mixture (66\%), while for selenium similar efficiencies were found in both sorbents, i.e. close to $80 \%$. 
Table 2. Maximum retention capacities (MRC) and efficiencies (E) obtained.

\begin{tabular}{llllll}
\hline \multirow{2}{*}{ Sorbent } & MRC & & E & \\
& $\left(\mathrm{mg} \mathrm{g}^{-1}\right)$ & & & $(\%)$ & \\
\cline { 2 - 3 } \cline { 5 - 6 } & As & Se & & As & Se \\
\hline ZT-6 & $0.35 \pm 0.04$ & $56.4 \pm 2.42$ & 2 & 83 \\
ZFT-11 & $20.5 \pm 1.43$ & $55.0 \pm 3.12$ & 66 & 77 \\
\hline
\end{tabular}

Different quantities of sulphur from the gasification atmosphere were also retained during the experiments. It should be pointed out that sulphur retention capacities ranging from 6 to $400 \mathrm{mg} \mathrm{g}^{-1}$, are described in the literature, ${ }^{7}$ and the retention mechanisms have been well established [1] [2]. Although in our retention experiments the MRC for sulphur was not achieved, from an analysis of the quantity of sulphur simultaneously retained, it was possible to estimate the "retention velocity" defined as the mg of element retained per minute. This value was then used to evaluate the retention of S together with As or Se. The average value of the adsorption velocities for arsenic, selenium and sulphur are given in Table 3. The maximum adsorption

Table 3. Adsorption velocities

\begin{tabular}{llll}
\hline Sorbent & As & Se & S \\
& $\left.(\mathrm{mg} \mathrm{min})^{-1}\right)$ & $\left(\mathrm{mg} \mathrm{min}^{-1}\right)$ & $\left.(\mathrm{mg} \mathrm{min})^{-1}\right)$ \\
\hline ZT-6 & 0.01 & 0.37 & 0.54 \\
ZFT-11 & 0.36 & 0.36 & 0.55 \\
\hline
\end{tabular}

velocity was obtained for sulphur, this being of the same order in both sorbents $(0.55$ $\left.\mathrm{mg} \min ^{-1}\right)$, while for arsenic and selenium the adsorption velocities were similar (0.36$0.37 \mathrm{mg} \mathrm{min}^{-1}$ ). The only exception was arsenic retention in the ZT-6 sorbent in which 
the adsorption velocity was $0.01 \mathrm{mg} \mathrm{min}^{-1}$. These results point to sulphur retention as the kinetically favoured process, while the capture of arsenic and selenium may be considered as secondary. This can be explained in two ways depending on i) whether sulphur retention in the sorbent and arsenic/selenium retention are independent processes or ii) whether arsenic and selenium react with the sulphur compounds formed in the sorbent. It should be pointed out that the thermally treated sorbents ZT-6 and ZFT-11, such as those used in the retention experiments, contained 6.8 and $33.6 \mathrm{mg} \mathrm{S}$ per g of sorbent respectively.

ZnSe was identified in the post retention experiments of selenium by XRD, in both the ZFT-11 and ZT-6 sorbents. However, if crystalline arsenic compounds were formed they must have been present in low quantities outside the detection limit of this technique as no new phases of arsenic were identified. Arsenic retained in ZFT-11 evaporated completely during the 3 hours thermal treatment of the sorbent postretention at $550^{\circ} \mathrm{C}$ (Table 4), suggesting reversible adsorption mechanisms or the

Table 4. Retention capacities before and after heating for three hours in a gas atmosphere free of trace elements.

\begin{tabular}{|c|c|c|c|c|}
\hline \multirow[t]{2}{*}{ Sorbent } & \multicolumn{2}{|l|}{$\begin{array}{l}\text { As } \\
\left(\mathrm{mg} \mathrm{g}^{-1}\right)\end{array}$} & \multicolumn{2}{|l|}{$\begin{array}{l}\text { Se } \\
\left(\mathrm{mg} \mathrm{g}^{-1}\right)\end{array}$} \\
\hline & Before & After & Before & After \\
\hline ZT-6 & - & - & $56.4 \pm 2.42$ & $33.4 \pm 3.28$ \\
\hline ZFT-11 & $20.5 \pm 1.43$ & $0.65 \pm 0.07$ & $55.0 \pm 3.12$ & $35.7 \pm 2.32$ \\
\hline
\end{tabular}

formation of species that decompose during heating in a gasification atmosphere. The selenium retained in both sorbents was only partially lost during heating, and in similar proportions in the ZFT-11 and ZT-6 sorbents (Table 4). Water solubility tests of the 
sorbent post-retention demonstrated that the arsenic and selenium species retained in all cases were water insoluble. All these data support the assumption that the retention mechanism may be a chemical reaction between the trace element in gas phase and the sorbent. The reactions can be predicted from thermodynamic data at equilibrium. The formation of new compounds with arsenic in ZT-6 was not to be expected from theoretical calculations and the low retention capacities achieved during the retention experiments confirmed this prediction. However, in the case of the ZFT-11 sorbent, a chemical reaction with arsenic may occur, as a result of which an insoluble compound that decomposes at $550^{\circ} \mathrm{C}$, might be formed. Fe-As associations wereidentified by SEM-EDX. FeAs is the most probable compound predicted for an As-Fe interaction in the experimental conditions, on the basis of thermodynamic equilibrium calculations. The reaction with $\mathrm{ZnFe}_{2} \mathrm{O}_{4}$ as sorbent can be formulated as follows [3]:

$\mathrm{ZnFe}_{2} \mathrm{O}_{4}+1 / 4 \mathrm{As}_{4}(\mathrm{~g})+2 \mathrm{H}_{2} \mathrm{~S}(\mathrm{~g})+2 \mathrm{H}_{2}(\mathrm{~g}) \leftrightarrow \mathrm{FeAs}+\mathrm{ZnS}+\mathrm{FeS}+4 \mathrm{H}_{2} \mathrm{O}(\mathrm{g})$

Similar MRCs were obtained in both sorbents for selenium, which is consistent with the similar reaction mechanism. ZnSe was the species identified by XRD in the post-retention sorbents. $\mathrm{ZnSe}$ is an insoluble compound that decomposes during a long period of heating in a reducing atmosphere. From equilibrium calculations, the formation of FeSe in low proportions can also be predicted in the metal oxide mixture containing Fe. Indeed, the results obtained in this work also point to the possible formation of this compound. However, the experimental results suggest that the formation of $\mathrm{ZnSe}$ is the more likely product of selenium retention. This is supported by the fact that a similar MRC and E, and a similar behaviour during post-retention tests were observed in both sorbents whith suggest that the retained product is the same in both cases, while in $\mathrm{Zn}_{2} \mathrm{TiO}_{4}$ only $\mathrm{ZnSe}$ with no FeSe may be formed. Consequently, the possible reactions that may give rise to $\mathrm{ZnSe}$ are [4-5]. 
$\mathrm{Zn}_{2} \mathrm{TiO}_{4}+\mathrm{H}_{2} \mathrm{Se}(\mathrm{g})+\mathrm{H}_{2} \mathrm{~S}(\mathrm{~g}) \leftrightarrow \mathrm{ZnSe}+\mathrm{ZnS}+\mathrm{TiO}_{2}+2 \mathrm{H}_{2} \mathrm{O}(\mathrm{g})$

$2 \mathrm{ZnFe}_{2} \mathrm{O}_{4}+\mathrm{H}_{2} \mathrm{Se}(\mathrm{g})+5 \mathrm{H}_{2} \mathrm{~S}(\mathrm{~g})+2 \mathrm{H}_{2}(\mathrm{~g}) \leftrightarrow \mathrm{ZnSe}+\mathrm{ZnS}+4 \mathrm{FeS}+8 \mathrm{H}_{2} \mathrm{O}(\mathrm{g})$

The behaviour of the sorbent during heating in an oxygen atmosphere is an indication of its future performance during regeneration processes. The results obtained in this work in trace element stability tests in an oxygen atmosphere show that arsenic is emitted in significant amounts, over a 6 hour period, while selenium is totally re-emitted (Table 5). The loss of these elements from the regenerable sorbents indicates that the elimination of arsenic and selenium from the sorbent is possible. These sorbents could therefore be reusable. Moreover, the elimination of arsenic and selenium predicted for the regeneration process has shown that it is necessary to consider the presence of toxic species in the regeneration processes when the sorbents are used for sulphur retention.

Table 5. Retention capacities before and after heating in an oxygen atmosphere at 600 ${ }^{\circ} \mathrm{C}$ for six hours.
As
Se

Sorbent $\quad\left(\mathrm{mg} \mathrm{g}^{-1}\right)$

$\left(\mathrm{mg} \mathrm{g}^{-1}\right)$

\begin{tabular}{|c|c|c|c|c|}
\hline & Before & After & Before & After \\
\hline ZT-6 & $0.37 \pm 0.04$ & $0.14 \pm 0.02$ & $58.4 \pm 3.13$ & $0.02 \pm 0.001$ \\
\hline ZFT-11 & $20.3 \pm 1.74$ & $5.17 \pm 0.26$ & $55.6 \pm 3.12$ & $0.02 \pm 0.002$ \\
\hline
\end{tabular}

\section{CONCLUSIONS}

From the results obtained in this work it can be concluded that the removal of the toxic species of arsenic and selenium may be achieved during desulphurisation processes that use certain metal oxide mixtures as solid sorbents. Although physical adsorption cannot be dismissed, the main mechanisms proposed for these retentions are chemical reactions 
that form water insoluble products. The results reinforce the possibility of simultaneously retaining trace elements of environmental concern other than sulphur in metal oxide mixtures and of recovering of these elements during the regeneration processes.

\section{ACKNOWLEDGEMENT}

This work was carried out with financial support from ECSC 7220-ED/069

\section{REFERENCES}

[1] Yrjas, P.; Lisa, K.; Hupa, M. Fuel 1996, 75(1):89-95.

[2] Abbasian, J.; Rehmat, A.; Leppin, D.; Banerjee, D.D. Fuel Process. Technol. 1990, 25(1), 1-15.

[3] Mitchell, S.C. Hot gas cleanup of sulphur, nitrogen, minor and trace elements, IEA Coal Research, ISBN 92-9029-317-9, December 1998.

[4] Lew, S.; Jothimurugesan, K.; Fkytani-Stephanopoulos, M. Ind. Eng. Chem. Res. 1989, 28(5), 535-541.

[5] Sasaoka, E. Energy \& Fuels 1994, 8(3), 763-769.

[6] Pineda, M.; Palacios, J.M.; Alonso, L.; García, E.; Moliner, R. Fuel 2000, 79(8), 885-895.

[7] Garcia, E.; Cilleruelo, C.; Ibarra, J. V.; Pineda, M.; Palacios, J. M. Ind. Eng. Chem. Res. 1997, 36(3), 846-853.

[8] Gupta, R.; Gangwal, S. K.; Jain, S. C. Energy \& Fuels 1992, 6(1), 21-27.

[9] CAA 1990, available in: http://www.epa.gov/air/oaq_caa.html.

[10] Swain, D.J. Trace elements in coal, Butterworth \& Co 1990.

[11] Meij, R. Fuel Process. Technol. 1994, 39(1-3), 199-217. 
[12] Martínez-Tarazona, M. R.; Spears, D. A. Fuel Process. Technol. 1996; 47(1), 79-92.

[13] Senior, C. L.; Bool III, L. E.; Morency, J. R. Fuel Process. Technol. 2000, 63(2-3), 109-124.

[14] Helble, J. J.; Mojtahedi, W.; Lyyränen, J.; Jokiniemi, J.; Kauppinen, E. Fuel 1996, 75(8), 931-939.

[15] Beishon, D. S.; Hood, J.; Vierrath, H. E. The fate of trace elements in the BGL gasifier in Sixth Annual International Pittsburgh Coal Conference 25-29 September 1989; 539.

[16] Díaz-Somoano,1 M.; Martínez-Tarazona, M. R. Fuel 2003, 82(2), 137-145.

[17] Mahuli, S.; Agnihotri, R.; Chauk, S.; Ghosh-Dastidar, A.; Fan, L.S. Environ. Sci. Technol. 1997, 31(11), 3226-3231.

[18] Agnihotri, R.; Chauk, S.; Mahuli, S.; Fan, L.S. Environ Sci. Technol. 1998, 32(12), 1841-1846.

[19] Ghosh-Dastidar, A.; Mahuli, S.; Agnihotri, R.; Fan, L.S. Environ Sci. Technol. 1996, 30(2), 447-452.

[20] Díaz-Somoano, M.; Martínez-Tarazona, M.R. J Chem. Technol. Biotechnol. 2002, 77(3), 396-402. 